\title{
Hospital Charge Variability across New York State: Sociodemographic Factors in Pituitary Surgery
}

\author{
Sarah M. Kidwai ${ }^{1}$ Anthony Yang ${ }^{1}$ Mingyang L. Gray ${ }^{1} \quad$ Sean McKee ${ }^{1} \quad$ Alfred Marc lloreta ${ }^{1}$ \\ Raj Shrivastava ${ }^{2}$ Satish Govindaraj ${ }^{1}$
}
1 Department of Otolaryngology-Head and Neck Surgery, Icahn School of Medicine at Mount Sinai, New York, New York, United States
2 Department of Neurosurgery, Icahn School of Medicine at Mount Sinai, New York, New York, United States

\begin{abstract}
Address for correspondence Sarah M. Kidwai, MD, Department of Otolaryngology-Head and Neck Surgery, Icahn School of Medicine at Mount Sinai, One Gustave L Levy Place, P.O. Box 1189, New York, NY 10029, United States (e-mail: sarah.kidwai@mountsinai.org).
\end{abstract}

J Neurol Surg B 2019;80:612-619.

\begin{abstract}
Keywords

- rhinology

- skull base

- pituitary adenoma

- charge variability

- hospital costs

Introduction Significant charge disparities exist across New York State (NYS). Race and income are associated with increased charges. To determine risk factor, we correlate hospital charges for pituitary surgery with socioeconomic factors. Additionally, we identify patients at risk for increased hospital charges and provide insight into cost-effective practices.

Methods Retrospective cohort study of the Statewide Planning and Research Cooperative System (SPARCS) database from the NYS Department of Health was conducted. The SPARCS database was reviewed. Patients who underwent transsphenoidal pituitary surgery from 1995 to 2015 were identified. Income and urban status were referenced from U.S. census data. Linear regression was performed to analyze the effect of sociodemographic factors, comorbidities, and complications on hospital charges while controlling for length of stay.

Results A total of 9,373 patients were identified. Black $(10.8 \%, p<0.001)$ and Asian (14.5\%, $p<0.001$ ) had higher hospital charges. Patients from nonurban cities (13.4\%, $p<0.001)$, Medicaid $(13.8 \%, p<0.001)$, and those from the 0 to 25 th $(9.1 \%$, $p<0.001)$ and 25 to 50th $(11.7 \%, p<0.001)$ income quartile had lower hospital charges. Patients with postoperative cerebrospinal fluid leak $(24.0 \%, p<0.001)$, diabetes insipidus (22.1\%, $p<0.001)$, smoking history $(11.8 \%, p<0.001)$, hypertension $(7.4 \%, p<0.001)$, and hypothyroidism $(6.9 \%, p<0.001)$ had higher hospital charges.

Conclusion Patients incurring higher chargers were more likely to have a smoking history, hypertension, hypothyroidism, and comorbidities. The determinants of this analysis may provide insight into barriers to patient access and cost improvement strategies. In addition, this emphasizes the need for future studies to create a risk stratification model, similar to those in other fields.
\end{abstract}

received

July 22, 2018

accepted

November 13, 2018

published online

January 4, 2019 (c) 2019 Georg Thieme Verlag KG

Stuttgart · New York
DOI https://doi.org/

10.1055/s-0038-1676839.

ISSN 2193-6331. 


\section{Introduction}

In the United States alone, more than 5,000 people undergo pituitary adenoma resection each year, with an associated annual cost of greater than $\$ 100$ million. ${ }^{1,2}$ Surgical therapy often involves a transsphenoid approach, through microscopy or endoscopy. A recent study compared health care costs of endoscopic transsphenoidal pituitary surgery to microscopic transsphenoidal pituitary surgery and found mean cost savings and utility gain marginally better for endoscopic transsphenoidal pituitary surgery, with reduced operative time and decreased nonrhinologic complications. ${ }^{3}$ Another recent study identified important cost drivers in transsphenoidal surgery, and emphasized identifying lowrisk patients a fast-track protocol for recovery including early ambulation, surgical step down care, and early discharge. ${ }^{4}$ Identifying such cost drivers and analyzing patient cost is essential to providing insight into health care disparities. Pituitary tumors occur in a diverse group of patients with different racial groups, insurance status, and comorbidities. By identifying specific characteristics that are associated with increased hospital charges, we hope to help to identify patients that may be at a higher risk for complications and increased hospital charges.

It has been suggested that higher costs and charges do not always correlate with improved outcomes. ${ }^{5}$ To help understand factors involved with hospital charges related to transsphenoidal pituitary surgery, we analyzed a cohort of patients across New York State (NYS) from 1995 to 2015. The purpose of our study was to establish geographic variations related to hospital charges across New York and to identify patient characteristics that are associated with increased hospital charges. This may provide help practitioners to riskstratify patients that have characteristics associated with increased hospital charges.

\section{Methods}

The SPARCS (Statewide Planning and Research Cooperative System) database is a comprehensive all-payer reporting system in NYS, containing patient level data on all hospital discharges. Patients who underwent transsphenoidal surgery for pituitary masses between January 01, 1995 and October 01, 2015 were identified using International Classification of Diseases, 9th Revision, Clinical Modification (ICD9-CM) diagnosis and procedure codes. We chose to examine only endoscopic pituitary procedures with current procedural terminology (CPT) code 62165 (neuroendoscopy procedures on the skull, meninges, and brain) to avoid additional heterogeneity. Patient demographics obtained included age, sex, ethnicity, race, income level, and zone improvement plan (ZIP) code of residence. Income of the patient was derived using the median income of the patient's ZIP code of residence from the United States (U.S.) census. Urban or rural classification of patient's residence and hospital location was also determined by linking the ZIP code of patient's residence or hospital to the U.S. census, respectively. Provider characteristics obtained included surgeon volume, hospital volume, and teaching status of the hospital. Teaching status was defined as hospitals receiving direct graduate medical education payment from Medicare. The volume of the surgeon and hospital were calculated by annual caseload of pituitary surgery. Surgeons and hospitals were then stratified into high (top quartile), medium (25-75th percentile), and low (bottom quartile) volume categories.

Comorbidities and complications for each patient were also assessed. Comorbidities were determined using diagnosis codes those were present on admission. Complications were determined as all other procedure and diagnosis codes not present on admission. Comorbidities assessed included hypertension, diabetes mellitus, panhypopituitarism, hypothyroidism, Cushing's syndrome, history of tobacco use, diabetes insipidus, visual disturbances, and epistaxis. The enhanced Charlson's comorbidity index (CCI) was also calculated. ${ }^{6}$ Complications assessed included diabetes insipidus, cerebrospinal fluid (CSF) leak, meningitis, and requiring a packed cell transfusion. The length of hospital stay for each patient admission was also evaluated.

The primary outcome of interest was hospital charges linked to the patients' admission. Hospital charges were adjusted for inflation using the consumer price index (CPI) for medical care from the Bureau of Labor Statistics. In this study, hospital charges indicate the actual cost of care or the amount received from third-party payers.

Univariate and multivariate linear regressions were used to assess the effect of patient and provider factors on total hospitalization charges. Length of stay and hospital charges underwent a logarithmic transformation before including it in the multivariate model. Statistical significance was set at $p<0.05$. All analyses were performed using Statistical Analytical Software 9.4. (Cary, North Carolina, United States)

\section{Results}

A total of 9,373 patients were admitted to a hospital with a principal diagnosis involving a neoplasm of the pituitary gland and principal procedure code involving an endoscopic transsphenoidal pituitary procedure between 1995 and 2015. Patient demographics are listed in - Table 1. The distribution of patient complications and comorbidities is shown in - Table 2. Hospital and surgeon characteristics are shown in - Table 3.

When controlling for patient characteristics and comorbidities, females were associated with a $3.41 \%$ less hospital charge compared with males ( $p=0.0013$ ). Patients aged 45 to 65 years had increased hospital charges by $4.26 \%$ and those over age 65 years by $3.43 \%$; however, only the former was statistically significant. In addition, Black race and Asian race were both associated with higher hospital charges when compared with White race, $10.88 \%(p<0.001)$ and $14.51 \%$ $(p<0.001)$, respectively. Average hospital charges distributed by race is shown in - Fig. 1. A higher $\mathrm{CCI}(1,2,3,4+)$ was associated with incrementally higher hospital charges when compared with a CCI of 0 by $8.89 \%, 12.39 \%, 20.49 \%, 23.91 \%$, respectively $(p<0.001)$. Patients with Medicaid insurance had $13.8 \%$ lower hospital charges compared with private 
Table 1 Patient demographics

\begin{tabular}{|c|c|c|}
\hline & & $n(\%)$ \\
\hline \multirow[t]{3}{*}{ Age $(y)$} & $<45$ & $3,241(35 \%)$ \\
\hline & $45-65$ & $4,148(44 \%)$ \\
\hline & $>65$ & $1,984(21 \%)$ \\
\hline \multirow[t]{2}{*}{ Sex } & Male & 4,569 (49\%) \\
\hline & Female & $4,804(51 \%)$ \\
\hline \multirow[t]{3}{*}{ Ethnicity } & Non-Hispanic & 7,389 (79\%) \\
\hline & Hispanic & $653(7 \%)$ \\
\hline & Unknown & $1,331(14 \%)$ \\
\hline \multirow[t]{5}{*}{ Race } & White & $5,262(56 \%)$ \\
\hline & Black & $1,603(17 \%)$ \\
\hline & Asian & 432 (5\%) \\
\hline & Other & $1,456(16 \%)$ \\
\hline & Unknown & $620(7 \%)$ \\
\hline \multirow[t]{4}{*}{ Insurance } & Private & $6,537(70 \%)$ \\
\hline & Medicaid & $745(8 \%)$ \\
\hline & Medicare & 1,799 (19\%) \\
\hline & Other & 292 (3\%) \\
\hline \multirow[t]{4}{*}{ Income quartile } & $76-100$ & $2,348(25 \%)$ \\
\hline & $51-75$ & $2,332(25 \%)$ \\
\hline & $26-50$ & $2,350(25 \%)$ \\
\hline & $0-25$ & $2,343(25 \%)$ \\
\hline \multirow[t]{2}{*}{ Patient residence } & Urban & 8,776 (94\%) \\
\hline & Rural & 597 (6\%) \\
\hline
\end{tabular}

insurance $(p<0.001)$, while patients with Medicare insurance had 6.94\% lower hospital charges compared with private insurance $(p=0.0002)$. Average hospital charges distributed by patient insurance is shown in - Fig. 2. Patient residence in a rural location was associated with a $13.37 \%$ lower hospital charge compared with patient residence in an urban location $(p<0.001)$.

While rural location of hospital was associated with a $19.96 \%$ increased hospital charge, this was not statistically significant. High hospital volume was associated with $30.66 \%$ increased hospital charges compared with low hospital volume $(p<0.001)$. Surgeon volume had no statistically significant association with hospital charge. Patients in the lowest and second lowest income quartile were associated with lower hospital charges by $9.08 \%$ and $11.77 \%$, respectively $(p<0.001)$. Average hospital charge distributed by income quartile is shown in - Fig. 3. Teaching status of the hospital was associated with a $14.51 \%$ lower hospital charge compared with a nonteaching hospital ( $p=0.0003)$.

The results of multivariate linear regression analysis to evaluate patient comorbidities and complications and their associated hospital charges is shown in - Table 4. Hypertension, hypothyroidism, history of tobacco use, diabetes insipidus, and visual disturbance were comorbidities associated
Table 2 Distribution of patient comorbidities and complications

\begin{tabular}{|c|c|c|}
\hline Comorbidities & & $n(\%)$ \\
\hline \multirow[t]{2}{*}{ Hypertension } & No & $5,992(64 \%)$ \\
\hline & Yes & $3,381(36 \%)$ \\
\hline \multirow[t]{2}{*}{ Diabetes mellitus } & No & $8,018(86 \%)$ \\
\hline & Yes & $1,355(14 \%)$ \\
\hline \multirow[t]{2}{*}{ Panhypopituitarism } & No & $9,002(96 \%)$ \\
\hline & Yes & $371(4 \%)$ \\
\hline \multirow[t]{2}{*}{ Hypothyroidism } & No & $8,018(86 \%)$ \\
\hline & Yes & $1,355(14 \%)$ \\
\hline \multirow[t]{2}{*}{ Cushing's syndrome } & No & $8,779(94 \%)$ \\
\hline & Yes & $594(6 \%)$ \\
\hline \multirow[t]{2}{*}{ History of tobacco use } & No & $8,946(95 \%)$ \\
\hline & Yes & $427(5 \%)$ \\
\hline \multirow[t]{2}{*}{ Diabetes insipidus } & No & 9,009 (96\%) \\
\hline & Yes & $364(4 \%)$ \\
\hline \multirow[t]{2}{*}{ Visual disturbance } & No & $8,493(91 \%)$ \\
\hline & Yes & $880(9 \%)$ \\
\hline \multirow[t]{2}{*}{ Epistaxis } & No & $9,363(100 \%)$ \\
\hline & Yes & $10(0 \%)$ \\
\hline \multirow[t]{5}{*}{ Charlson's comorbidity index } & 0 & $6,869(73 \%)$ \\
\hline & 1 & $1,878(20 \%)$ \\
\hline & 2 & $422(5 \%)$ \\
\hline & 3 & $112(1 \%)$ \\
\hline & $4+$ & $92(1 \%)$ \\
\hline \multicolumn{3}{|l|}{ Complications } \\
\hline \multirow[t]{2}{*}{ Diabetes insipidus } & No & $8,938(95 \%)$ \\
\hline & Yes & $435(5 \%)$ \\
\hline \multirow[t]{2}{*}{ CSF leak } & No & 9,262 (99\%) \\
\hline & Yes & $111(1 \%)$ \\
\hline \multirow[t]{2}{*}{ Meningitis } & No & $9,348(100 \%)$ \\
\hline & Yes & $25(0 \%)$ \\
\hline \multirow[t]{2}{*}{ Packed cell transfusion } & No & $9,196(98 \%)$ \\
\hline & Yes & $177(2 \%)$ \\
\hline
\end{tabular}

Abbreviation: CSF, cerebrospinal fluid.

with increased hospital charges, with the highest percent increases with the latter three. All complications were associated with increased hospital charges.

\section{Discussion}

In multiple specialties, hospital charge variability exists through different geographic locations, patient characteristics, and hospital characteristics. ${ }^{5,7,8}$ Lee et al showed that there is significant variation in charges and costs for transsphenoidal surgery within New York. ${ }^{9}$ While they studied 
Table 3 Hospital and surgeon characteristics

\begin{tabular}{|l|l|l|}
\hline Location of hospital & Urban & $9,360(100 \%)$ \\
\hline & Rural & $13(0 \%)$ \\
\hline Hospital volume & Low & $629(7 \%)$ \\
\hline & Medium & $1,235(13 \%)$ \\
\hline & High & $7,509(80 \%)$ \\
\hline Surgeon volume & Low & $1,012(11 \%)$ \\
\hline & Medium & $1,362(15 \%)$ \\
\hline Teaching status & High & $6,999(75 \%)$ \\
\hline & Nonteaching & $175(2 \%)$ \\
\hline & Teaching & $9,198(98 \%)$ \\
\hline
\end{tabular}

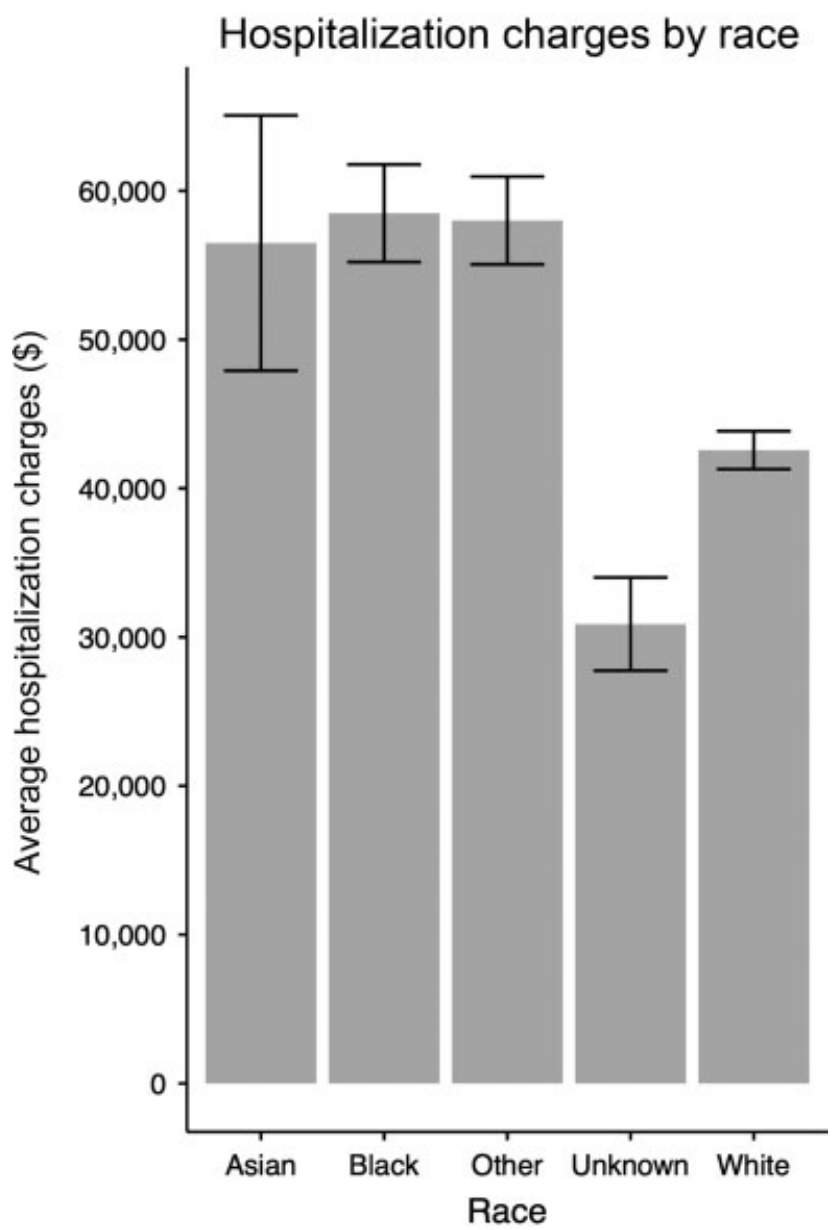

Fig. 1 Average hospitalization charge by race.

hospital costs and charges and cost-to-charge ratios, they did not evaluate patient and hospital characteristics and their relation to hospital charge. By studying these factors, we can better understand variations in health care costs and thereby, instrument approaches to reduce disparities in hospital charge.

Several studies illustrate health care disparities between men and women and between difference races. ${ }^{10-12}$ For example, Schneider et al showed that Hispanic ethnicity

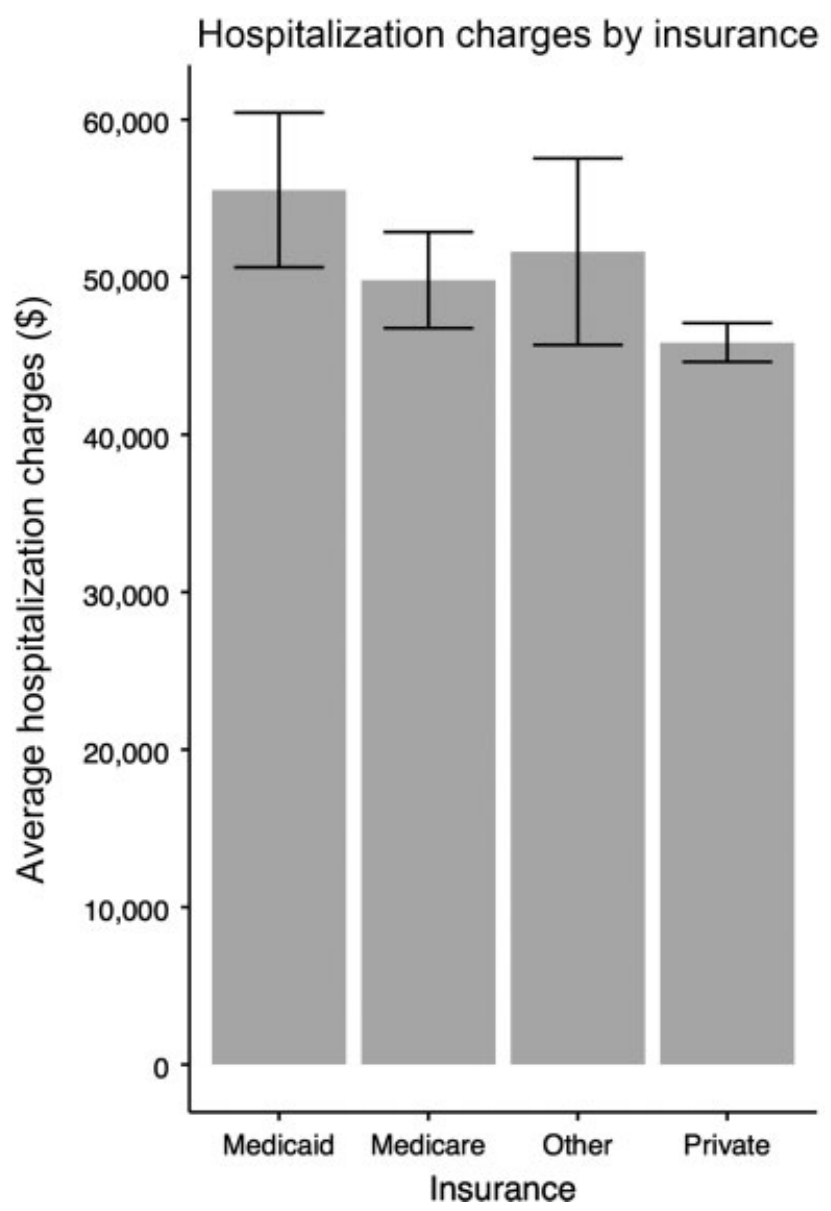

Fig. 2 Average hospitalization charge by insurance.

was an independent risk factor for mortality after carotid endarderectomy. ${ }^{12}$ In a univariate analysis, we found that Black and Asian races were associated with statistically significant increased hospital charges (28.73 and 24.34\%, respectively). This same significance upheld in the multivariate analysis when controlling for patient, hospital, and surgeon characteristics with 10.88 and $14.51 \%$ increased hospital charge, respectively. This suggests that while there may be patient, hospital, and surgeon characteristics that drive these differences, when these are controlled for, there is still an associated increase in hospital charges when compared with White patients.

The CCI scores 19 different categories of comorbidities, and predicts 10 -year mortality for a patient. A higher score is indicative of a greater 10 -year mortality risk. ${ }^{13}$ Previous studies in the literature have shown higher charges associated with a higher CCI. For example, Fu et al found that higher vaginal and vulvar cancer charges were associated with higher $\mathrm{CCl}{ }^{14}$ Similarly, we found increased hospital charges associated with increased $\mathrm{CCI}$ in both our univariate and multivariate analysis. It is crucial to note that $73 \%$ of our cohort had a $\mathrm{CCI}$ of 0 . Another study evaluating health care costs of patients who underwent acoustic neuroma surgery, found that a higher comorbidity index independently predicted a discharge disposition that was other than routine. ${ }^{15}$ 


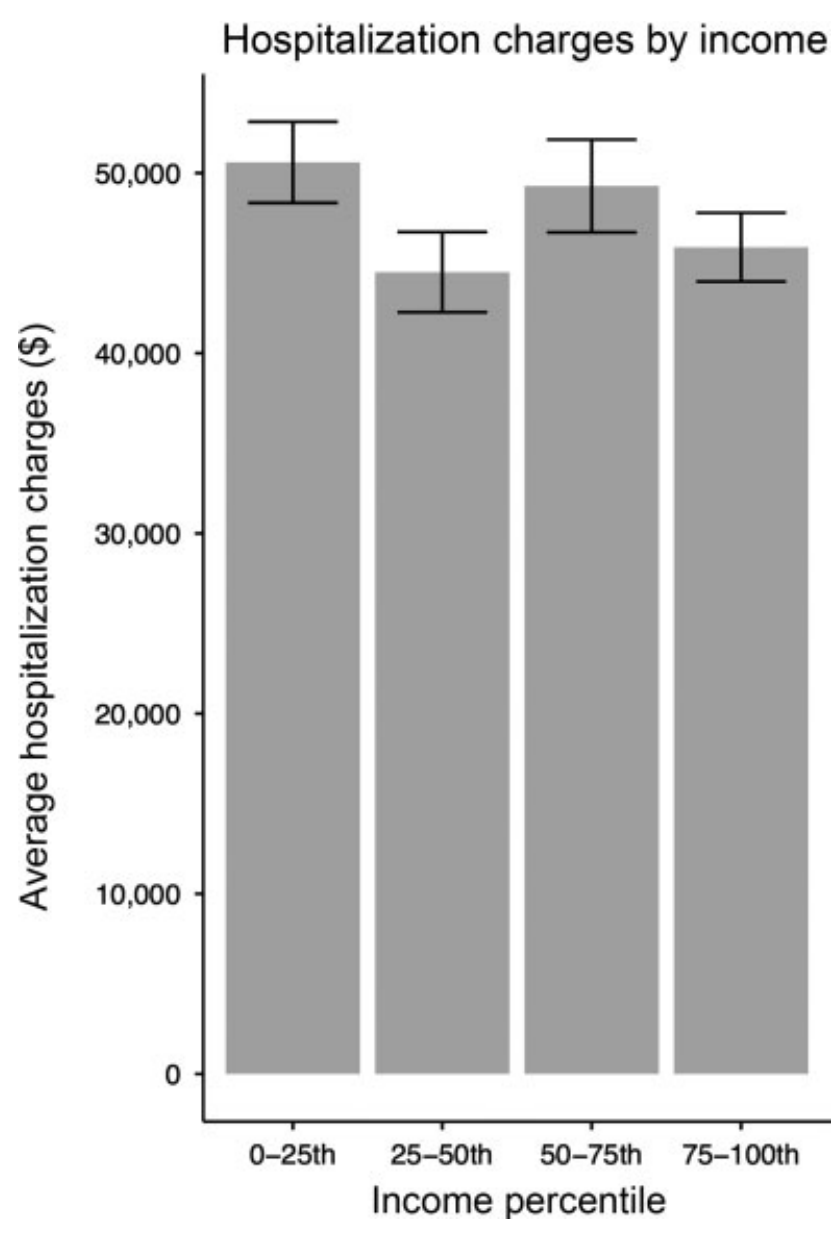

Fig. 3 Average hospitalization charge by income.

We also found in our cohort that patients with Medicare and Medicaid insurance had significantly lower charges than those with private insurance. In addition, we found that those from the lowest income quartile and the second lowest income quartile had significantly lower hospital charges when compared with patients in the highest income quartile. We suspect that patients in the lower quartiles were those with nonprivate insurance, which explains these trends. In the study by Sonig et al, they found that patients with private insurance and higher household income had significant better outcomes after surgery. ${ }^{15}$

In regards to hospital characteristics, we found that high volume hospitals had higher associated hospital charges compared with low volume hospitals, while teaching hospitals had lower associated hospital charges compared with nonteaching hospitals. This is a similar finding to the study by Sonig et al which also demonstrated that teaching hospitals have lower hospitalization costs than nonteaching hospitals; however, this trend was not significant in their multivariate analysis. ${ }^{15}$ In other studies, treatment at a teaching hospital was associated with increased hospital cost but overall survival and mortality was lower at teaching hospitals; however, this was mainly studied in the orthopaedic population. ${ }^{16,17}$ We did see in our cohort that $80 \%$ of hospitals were high volume and $98 \%$ of hospitals were teaching hospitals. Because of the multidisciplinary approach to transsphenoidal surgery and the need for neurosurgery, otolaryngology, and at times, interventional radiology availability, we expect such skewed data.

Finally, we found that nearly all comorbidities and all complications were associated with increased hospital charge in our univariate analysis. When controlled for patient and hospital factors, we found that hypertension, hypothyroidism, history of tobacco use, diabetes insipidus, and visual disturbances were comorbidities associated with higher hospital charges. We suspect this to be the case as each of these comorbidities indicates either a larger pituitary lesion or secreting-pituitary mass that requires more extensive resection and/or the assistance of endocrinology and postoperative intensive care. A history of tobacco use, while present in only $5 \%$ of our cohort, was associated with an $11.79 \%$ increased hospital charge. It has been well documented that smoking has a detrimental impact on health and is associated with comorbidities. ${ }^{18}$ As illustrated previously, we see an increased charge is associated with an increased comorbidity index and similarly we can explain the increased hospital charge tassociated with tobacco use. We also observed that complications including diabetes insipidus, CSF leak, meningitis, and requirement of packed cell transfusion were also associated with increased hospital charges. This is expected as these complications often require a higher level of care or increased length of stay.

In our study, we highlight a few major concerns in the care of patients with pituitary adenoma. We see that patients of Black and Asian races have increased hospital charges which illustrated that disparity in health care expenditures exists. In addition, we see that patients with comorbidity and/or complications were also associated with higher hospital charges. The most ideal approach to health care should reduce health care costs and charges, while maintaining safe and efficient care. Those patients with comorbidities and complications often need a higher level of care in an intensive care unit and with consultation from different specialties. Karsy et al suggested stratification of patients into low-risk and high-risk cohorts, to select patients that require more acute intensive care monitoring versus those that can be monitoring in a surgical step down setting. ${ }^{4}$ Others have also proved that using a short-stay protocol for patients after pituitary surgery was safe and associated with a low rate of complications and readmissions. ${ }^{19,20}$ In urology, similar studies have been conducted to risk stratify patients that require surgical intensive care unit admission after radical cystectomy and urinary diversion procedures. ${ }^{21}$ In pediatric surgery, a prospective study was conducted to identify a risk stratification system correlating outcome and resource utilization with increasing grade of perforated appendicitis. $^{22}$ In our study, we identify factors that are associated with increased cost. Our next step to build a risk stratification model is to conduct a prospective study to assess if these identified factors can predict complications, length of hospital stay, and morbidity after transsphenoidal surgery. Next, we would implement a risk stratification model in a prospective study. 
Table 4 Multivariate linear regression of patient comorbidities and complications

\begin{tabular}{|c|c|c|c|}
\hline & & Percentage change $(95 \% \mathrm{Cl})$ & $p$-Value \\
\hline \multirow[t]{3}{*}{ Age $(y)$} & $<45$ & Ref & \\
\hline & $45-65$ & $4.26 \%(1.79,6.72)$ & 0.0007 \\
\hline & $>65$ & $3.43 \%(-0.55,7.41)$ & 0.0916 \\
\hline \multirow[t]{2}{*}{ Sex } & Male & Ref & \\
\hline & Female & $-3.41 \%(-5.49,-1.33)$ & 0.0013 \\
\hline \multirow[t]{3}{*}{ Ethnicity } & Non-Hispanic & Ref & \\
\hline & Hispanic & $2.1 \%(-2.23,6.44)$ & 0.3417 \\
\hline & Unknown & $-36.79 \%(-40.44,-33.13)$ & $<0.0001$ \\
\hline \multirow[t]{5}{*}{ Race } & White & Ref & \\
\hline & Black & $10.88 \%(7.83,13.93)$ & $<0.0001$ \\
\hline & Asian & $14.51 \%(9.51,19.5)$ & $<0.0001$ \\
\hline & Other & $24.05 \%(20.84,27.27)$ & $<0.0001$ \\
\hline & Unknown & $-9.11 \%(-14.19,-4.04)$ & 0.0004 \\
\hline \multirow[t]{4}{*}{ Insurance } & Private & Ref & \\
\hline & Medicaid & $-13.8 \%(-17.78,-9.81)$ & $<0.0001$ \\
\hline & Medicare & $-6.94 \%(-10.58,-3.3)$ & 0.0002 \\
\hline & Other & $-8.19 \%(-14.13,-2.26)$ & 0.0068 \\
\hline \multirow[t]{2}{*}{ Patient residence } & Urban & Ref & \\
\hline & Rural & $-13.37 \%(-17.68,-9.06)$ & $<0.0001$ \\
\hline \multirow[t]{2}{*}{ Location of hospital } & Urban & Ref & \\
\hline & Rural & $19.96 \%(-7.73,47.65)$ & 0.1577 \\
\hline \multirow[t]{3}{*}{ Hospital volume } & Low & Ref & \\
\hline & Medium & $8.14 \%(3.08,13.2)$ & 0.0016 \\
\hline & High & $30.66 \%(25.92,35.39)$ & $<0.0001$ \\
\hline \multirow[t]{3}{*}{ Surgeon volume } & Low & Ref & \\
\hline & Medium & $-3.1 \%(-7.27,1.07)$ & 0.1456 \\
\hline & High & $-4.11 \%(-7.83,-0.39)$ & 0.0303 \\
\hline \multirow[t]{4}{*}{ Income quartile } & $76-100$ & Ref & \\
\hline & $51-75$ & $-2.39 \%(-5.3,0.52)$ & 0.1074 \\
\hline & $26-50$ & $-11.77 \%(-14.74,-8.79)$ & $<0.0001$ \\
\hline & $0-25$ & $-9.08 \%(-12.2,-5.96)$ & $<0.0001$ \\
\hline \multirow[t]{2}{*}{ Teaching status } & Nonteaching & Ref & \\
\hline & Teaching & $-14.51 \%(-22.39,-6.64)$ & 0.0003 \\
\hline \multicolumn{4}{|l|}{ Comorbidities } \\
\hline \multirow[t]{2}{*}{ Hypertension } & No & Ref & \\
\hline & Yes & $7.36 \%(5.01,9.71)$ & $<0.0001$ \\
\hline \multirow[t]{2}{*}{ Diabetes mellitus } & No & Ref & \\
\hline & Yes & $-3.48 \%(-7.51,0.55)$ & 0.0907 \\
\hline \multirow[t]{2}{*}{ Panhypopituitarism } & No & Ref & \\
\hline & Yes & $1.58 \%(-3.74,6.9)$ & 0.5603 \\
\hline \multirow[t]{2}{*}{ Hypothyroidism } & No & Ref & \\
\hline & Yes & $6.89 \%(3.94,9.84)$ & $<0.0001$ \\
\hline Cushing's syndrome & No & Ref & \\
\hline
\end{tabular}


Table 4 (Continued)

\begin{tabular}{|l|l|l|l|}
\hline & & Percentage change (95\% Cl) & $p$-Value \\
\hline & Yes & $-1.22 \%(-5.57,3.12)$ & 0.581 \\
\hline History of tobacco use & No & Ref & \\
\hline & Yes & $11.79 \%(6.87,16.72)$ & $<0.0001$ \\
\hline Diabetes insipidus & No & Ref & \\
\hline & Yes & $16.15 \%(10.79,21.51)$ & $<0.0001$ \\
\hline Visual disturbance & No & Ref & \\
\hline & Yes & $22.41 \%(18.86,25.97)$ & $<0.0001$ \\
\hline Epistaxis & No & Ref & \\
\hline & Yes & $-18.87 \%(-49.98,12.25)$ & 0.2346 \\
\hline Charlson's comorbidity index & 0 & Ref & \\
\hline & 1 & $8.89 \%(5.55,12.23)$ & $<0.0001$ \\
\hline & 2 & $12.39 \%(6.92,17.87)$ & $<0.0001$ \\
\hline & 3 & $20.49 \%(10.72,30.25)$ & $<0.0001$ \\
\hline & $4+$ & $23.91 \%(13.32,34.5)$ & $<0.0001$ \\
\hline Complications & & \\
\hline Diabetes insipidus & & Ref & \\
\hline & No & $22.14 \%(17.21,27.07)$ & $<0.0001$ \\
\hline CSF leak & Yes & Ref & $<0.0001$ \\
\hline & No & $23.98 \%(14.47,33.49)$ & $<0.0001$ \\
\hline Meningitis & Yes & Ref & \\
\hline & No & $33.76 \%(13.69,53.84)$ & 0.001 \\
\hline Packed cell transfusion & Yes & Ref & \\
\hline & No & $17.17 \%(9.53,24.82)$ & $<$ \\
\hline
\end{tabular}

Abbreviations: $\mathrm{Cl}$, confidence interval; CSF, cerebrospinal fluid; Ref, reference.

Note: Multivariate analysis was adjusted for length of stay.

Our study is not without its limitations. We used a statewide database to perform a retrospective review which only captures data from NYS and cannot be generalizable to all other populations. The NYS population includes both urban and nonurban populations and thus, these results may only be generalizable to similar populations. In addition, the database relies on accurate diagnostic and procedural coding and entry by hospitals which is subject to error. Race and ethnicity classifications are extracted from hospital records and may not be accurate. Surgeon and patient income level is derived from home ZIP codes and contain significant heterogeneity. The total hospital charges referred to in this study indicate the actual cost of care or the amount received from third-party payers. Because of the limitations of the database, we were only able to capture complications and comorbidities that occurred during the patient's inpatient stay, so outpatient costs are not accounted for. We were also unable to capture surgery characteristics, such as tumor size, presence or absence of compressive symptoms and hormonal disturbances, and whether surgery was a primary or a revision surgery. Finally, pituitary surgery and management of these patients has changed drastically over the time period studied. Preoperative, intraoperative, and postoperative care has changed and the volume of pituitary surgery has also increased. When looking at the hospital charges for pituitary surgery throughout NYS, we saw increase in charges, which is likely attributed to this change in management of these patients and the increase in volume.

\section{Conclusion}

Patients in NYS who are associated with increased hospital charges are those of Black or Asian race, aged 45 to 65 years, comorbidities and complications during hospital stay. Patients of the lower income quartiles and those receiving care at a teaching hospital had decreased hospital charges. We demonstrate that a racial and economic disparity exists within the field of transsphenoidal surgery and this is further compounded by patient comorbidities and complications. Further population health studies are needed to clarify why such racial disparities exist. Risk stratification studies to identify patients that can be treated with an early discharge disposition and those that require additional monitoring and intensive care are also needed. 
Meeting Information

Podium presentation at the Triological Society Combined Sections Meeting, Scottsdale, Arizona, U.S.A.

Funding and Conflicts of Interest

The authors have no funding, financial relationships, or conflicts of interest to disclose.

\section{References}

1 Melmed S, Kleinberg D. Pituitary masses and tumors. In: Melmed S, Polonsky KS, Larsen PR, Kronenberg HM, eds. Williams Textbook of Endocrinology. 13th ed. Philadelphia: Elsevier; 2017: 232-299

2 Asemota AO, Ishii M, Brem H, Gallia GL. Comparison of complications, trends, and costs in endoscopic vs microscopic pituitary surgery: analysis from a US health claims database. Neurosurgery 2017;81(03):458-472

3 Ament JD, Yang Z, Khatchadourian V, Strong EB, Shahlaie K. Costeffectiveness of endoscopic versus microscopic transsphenoidal surgery for pituitary adenoma. World Neurosurg 2018;110: e496-e503

4 Karsy M, Brock AA, Guan J, Bisson EF, Couldwell WT. Assessment of cost-drivers in transsphenoidal approaches for resection of pituitary tumors using the value-drive outcome database. World Neurosurg 2017;105:818-823

5 Newhouse JP, Garber AM. Geographic variation in health care spending in the United States: insights from an Institute of Medicine report. JAMA 2013;310(12):1227-1228

6 Quan H, Sundararajan V, Halfon P, et al. Coding algorithms for defining comorbidities in ICD-9-CM and ICD-10 administrative data. Med Care 2005;43(11):1130-1139

7 Robinson JC, Pozen A, Tseng S, Bozic KJ. Variability in costs associated with total hip and knee replacement implants. J Bone Joint Surg Am 2012;94(18):1693-1698

8 Robinson BR, Pritts TA, Hanseman DJ, Wilson GC, Abbott DE. Cost discrepancies for common acute care surgery diagnoses in Ohio: influences of hospital characteristics on charge and payment differences. Surgery 2014;156(04):814-822

9 Lee CC, Kimmell KT, Lalonde A, et al. Geographic variation in cost of care for pituitary tumor surgery. Pituitary 2016;19(05):515-521

10 Williams JS, Bishu K, Dismuke CE, Egede LE. Sex differences in healthcare expenditures among adults with diabetes: evidence from the medical expenditure panel survey, 2002-2011. BMC Health Serv Res 2017;17(01):259

11 Propper B, Black JH III, Schneider EB, et al. Hispanic ethnicity is associated with increased costs after carotid endarterectomy and carotid stenting in the United States. J Surg Res 2013;184(01): 644-650

12 Schneider EB, Black JH III, Hambridge HL, et al. The impact of race and ethnicity on the outcome of carotid interventions in the United States. J Surg Res 2012;177(01):172-177

13 Charlson ME, Pompei P, Ales KL, MacKenzie CR. A new method of classifying prognostic comorbidity in longitudinal studies: development and validation. J Chronic Dis 1987;40(05): 373-383

14 Fu S, Lairson DR, Chan W, Wu CF, Ramondetta L. Mean medical costs associated with vaginal and vulvar cancers for commercially insured patients in the United States and Texas. Gynecol Oncol 2018;148(02):342-348

15 Sonig A, Khan IS, Wadhwa R, Thakur JD, Nanda A. The impact of comorbidities, regional trends, and hospital factors on discharge dispositions and hospital costs after acoustic neuroma microsurgery: a United States nationwide inpatient data sample study (2005-2009). Neurosurg Focus 2012;33(03):E3

16 McGuire KJ, Chacko AT, Bernstein J. Cost-effectiveness of teaching hospitals for the operative management of hip fractures. Orthopedics 2011;34(10):e598-e601

17 Taylor DH Jr, Whellan DJ, Sloan FA. Effects of admission to a teaching hospital on the cost and quality of care for Medicare beneficiaries. N Engl J Med 1999;340(04):293-299

18 Goodchild M, Nargis N, Tursan d'Espaignet E. Global economic cost of smoking-attributable diseases. Tob Control 2018;27(01): $58-64$

19 Thomas JG, Gadgil N, Samson SL, Takashima M, Yoshor D. Prospective trial of a short hospital stay protocol after endoscopic endonasal pituitary adenoma surgery. World Neurosurg 2014;81 $(3,4): 576-583$

20 Sarkiss CA, Lee J, Papin JA, et al. Pilot study on early postoperative discharge in pituitary adenoma patients: effect of socioeconomic factors and benefit of specialized pituitary centers. J Neurol Surg B Skull Base 2015;76(04):323-330

21 Dahm P, Tuttle-Newhall JE, Nimjee SM, Byrne RR, Yowell CW, Price DT. Indications for admission to the surgical intensive care unit after radical cystectomy and urinary diversion. J Urol 2001;166 (01):189-193

22 Yousef Y, Youssef F, Dinh T, et al. Risk stratification in pediatric perforated appendicitis: prospective correlation with outcomes and resource utilization. J Pediatr Surg 2018;53(02):250-255 